\title{
Factors influencing MAC reduction after cardiopulmonary bypass in dogs
}

\author{
Michael W. Neumeister MD, * \\ Gefeng Li MD,* \\ Gwen Williams Bsc, ${ }^{\dagger}$ \\ Greg Doak MD FRCPC, ${ }^{\dagger}$ \\ John A. Sullivan MD FRCsC, * \\ Richard I. Hall MD FRCPC ${ }^{\star \ddagger}$
}

Background: Anaesthetic requirements may be reduced following surgery employing cardiopulmonary bypass (CPB). This study, in dogs, determined the roie of a) volatile agents (enflurane [B] vs isoflurane [D], b) oxygenator (bubble $[B]$ is membrane [MD), and c) presence [FL] is absence [NoFL] of an in-line arterial fitter in the bypass circuit in attering anaesthetic requirements following CPB.

Methods: Male mongrel dogs were anzesthetized with either enflurane $(n=24)$ or isoflurane $(n=24)$. They were randomly assigned to one of eight groups ( $n=6$ per group); Group I (E/B/FL), Group 2 (EMM/FL), Group 3 (E/MNoFL), Group 4 (E/B/NoFL), Group 5 (I/M/FL), Group 6 (I/B/FL), Group 7 (IM/NoFL) or Group 8 (I/BNoFL). MAC was determined using the tail-clamp method at hourly intervals, twice before and three times after a one hour normothermic perfusion using aortoatrial cannulation and CPB.

Results: Prior to CPB, MAC was reproducible (enflurane: $M A C 12.17 \pm 0.29$ vs MAC2 2.14 $\pm 0.28 \%$; isoflurane: $\mathrm{MACl} 1.42 \pm 0.31$ is MAC2 I.41 $\pm 0.33 \%$ ) and differed among groups only for the volatile agent employed. Following CPB, MAC was reduced in all groups ( $P<0.05$ vs pre-CPB measurements) except Group I (E/B/FL). The degree of MAC reduction in other groups ranged from 39-64\% and was not different based on type of agent employed, use of a membrane or bubble oxygenator, or presence or absence of an in-line arterial fitter.

Conclusion: In dogs, $M A C$ reduction following CPB was variable, not related to type of volatile agent employed, use of a membrane or bubble oxygenator, or presence or absence of an in-line arterial filter. The explanation for reductions in anaesthetic requirements following CPB in this model remains speculative.

Objectif : On peut observer une diminution du besoin d'anesthésie après une intervention sous circulation extracorporelle (CEC). Cette étude réalisée chez des chiens visait à déterminer l'influence sur l'attération du besoin d'anesthésie apres la CEC : a) de l'agent volatil (enflurane [B] vs isoflurane [D] ; b) de l'oxygénateur (bulles [B] vs membrane [M] et $c$ ) de la présence [FL] vs l'absence [noFL] d'un filtre artériel en ligne sur le circuit extracorporel.

Méthodes : Des chiens måles de race commune ont été anesthésiés soit avec de l'enflurane $(n=24)$ soit avec de l'isofiurane $(n=24)$. Ils ont été répartis aléatoirement en huit groupes ( $n=6$ par groupe): Groupe I $(E / B / F L)$, Groupe 2(EM/FL), Groupe 3 (E/M/hoFL), Groupe 4 (E/B/noFL), Groupe 5 (IM/FL), Groupe 6 (//B/FL), Groupe 7 (IM/noFL) ou Groupe $8(\mathrm{I} / \mathrm{B} / \mathrm{noFL})$. La méthode du pincement de la queue aux heures a servi à déterminer le MAC, deux fois avant et trois fois apres une heure de perfusion normothermique sous CEC par canulation aortoatriale.

Résultats : Avant la CEC, le MAC était reproductible (enflurane MACI 2,17 $\pm 0,29$ vs MAC2 2,14 $\pm 0,28 \%$; isoflurane : MACl 1,42 $\pm 0,31$ vs MAC2 $1,41 \pm 0,33 \%$ ) et ne différait entre les groupes que selon l'agent volatil utilisé. Aprés la CEC, le MAC était réduit dans tous les groupes $(P<0,05$ vs les mesures pré-CEC) excepté dans le Groupe I (E/B/FL). Le degré de réduction du MAC dans les autres groupes s'étendait sur une gamme de 39 à $64 \%$ et ne differait pas selon l'agent, l'oxygénateur à membrane ou à bulles et la présence ou l'absence d'un filtre artériel en ligne.

Conclusion : Chez des chiens après la CEC, la réduction du MAC variait, mais sans relation avec l'agent volatil administré, l'utilisation d'un oxygénateur à membrane ou à bulle et la présence ou l'absence d'un filtre artériel en ligne. Sur ce modèle, l'explication de la réduction du besoin anesthésique demeure hypothétique.

From the Departments of Anaesthesia, ${ }^{\dagger}$ Surgery, ${ }^{*}$ and Pharmacology, ${ }^{\ddagger}$ Dalhousie University, Halifax, Nova Scotia, Canada. Supported by the New Brunswick Heart and Stroke Foundation. Dr. Hall is a PMAC/MRC Health Research Foundation Scholar. Address correspondence to: Dr. Richard Hall, c/o Department of Anaesthesia, Queen Elizabeth II Health Seiences Centre, Halifax Infirmary Site, 1796 Summer Street, Halifax, Nova Scotia, Canada B3H 3A7.

Presented, in part, at the IARS 22nd Annual Congress, Orlando, Florida, March 1994.

Accepted for publication July $1,1997$. 


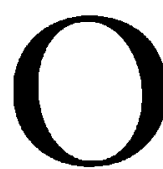

UR clinical impression is that anaesthetic requirements are altered following hypothermic cardiopulmonary bypass (CPB). Previous work from this laboratory has shown that, following cardiopulmonary bypass in dogs, the anaesthetic requirements for enflurane were reduced. ${ }^{1}$ At that time we speculated that the reduction in enflurane MAC (minimum alveolar concentration) was secondary to microemboli. Other investigators, however, could not confirm our original observations in the same animal model. ${ }^{2}$ Subsequent studies by these investigators have shown alterations in anaesthetic requirements post-CPB which might be due to differing effects of anaesthetics on inhibitory or excitatory pathways within the spinal cord $\mathrm{d}^{3,4}$ or to the residual effects of hypothermia. ${ }^{5,6}$ However, we could not find an independent effect of hypothermia and, in addition, the degree of MAC reduction post-CPB was unaffected by manipulation of arterial carbon dioxide tension (factors known to affect cerebral blood flow and thus delivery of microemboli) ${ }^{?}$

To clarify further what factors affect changes in anaesthetic requirements post- $\mathrm{CPB}$, this investigation sought to examine the role that volatile anaesthetic agents might play, and to determine the effect of strategies designed to prevent microemboli released during $\mathrm{CPB}$ from reaching the cerebral circulation (membrane oxygenator and presence of an in-line arterial filter), in altering MAC post-CPB. Our hypothesis was that there would be no difference in the degree of $\mathrm{MAC}$ reduction following CPB employing enflurane or isoflurane anaesthesia, and that the use of a membrane oxygenator and of an in-line arterial filter would lessen the impact of $\mathrm{CPB}$ on reduction of $\mathrm{MAC}$.

\section{Methods and materials}

This study was approved by the Dalhousie University Animal Care and Use Committee and followed the standards established by the Canadian Council of Animal Care. Fasted, hydrated mongrel dogs $(n=48)$ weighing $20 \pm 2 \mathrm{~kg}$ (all results mean $\pm S D$ ) were anaesthetized by a specialized mask with enflurane $(n=24)$ or isoflurane $(n=24)$ in oxygen. Following induction of anaesthesia, tracheal intubation and $i v$ cannulation were carried out. Anaesthesia was maintained via a calibrated vaporizer by enflurane or isoflurane in oxygen as appropriate according to the randomized treatment design. Heart rate and rhythm were recorded continuously. The femoral artery was cannulated for monitoring of systemic blood pressure and for the procurement of blood for gas analysis. A flow-directed pulmonary artery catheter was inserted into the pulmonary artery via the right external jugular vein for measurement of pulmonary artery, central venous, and pulmonary artery occlusion pressures, and cardiac output using a thermodilution technique (Abbott Model No. 3300). All variables were continuously recorded on a Hewlett Packard $^{\mathrm{R}}$ recording device Model No. HP7754A. Temperature was recorded from the tip of the pulmonary artery catheter and from the bladder via a urinary catheter. End-tidal volatile agent concentration was measured via a Puritan-Bennett Anesthesia Agent Monitor $^{\mathrm{R}}$ (sensitivity $0.1 \%$ ) which was calibrated immediately before each experiment using the agent to which the dog was randomized. Arterial blood gases and haematocrit were measured following determination of each MAC. Using a modification of the tail-clamp method of Eger $e t a l^{8}{ }^{8} \mathrm{MAC}$ was determined. In brief, a $25 \mathrm{~cm}$ sponge clamp was applied to the base of the dog's tail and closed to full ratchet lock. The tail was manipulated for one minute or until gross purposeful movement was obtained. Swallowing, or increased respiratory effort, did not constitute gross purposeful movement. If movement occurred, the end-tidal anaesthetic concentration was increased by $0.2 \%$, allowed to stabilize for $15 \mathrm{~min}$, and the tail-clamp procedure repeated. Similarly, if no movement occurred, the endtidal anaesthetic concentration was reduced by $0.2 \%$, allowed to stabilize for $\mathbf{1 5} \mathrm{min}$, and the tail-clamp procedure repeated. We required three determinations of response (i.e., movement-no movement-movement or no movement-movement-no movement) to estimate MAC which was then taken as the end-tidal concentration mid-way between that concentration which did and did not produce gross purposeful movement. Warming blankets maintained body temperature in the normal range.

On the morning of surgery, the animals were randomly assigned to one of eight groups ( $n=6$ per group) based on whether they received enflurane $[E]$ or isoflurane $[\mathrm{I}]$, a membrane $[\mathrm{M}]$ or bubble $[\mathrm{B}]$ oxygenator was utilized in the CPB circuit, and whether an in-line arterial filter was present $[\mathrm{FL}]$ or absent $[\mathrm{NoFL}]$ in the circuit: Group l (E/B/FL), Group 2 (E/M/FL), Group 3 (E/M) NoFL), Group 4 (E/B/NoFL), Group $5(\mathrm{I} / \mathrm{M} / \mathrm{FL})$, Group 6 (I/B/FL), Group 7 (I/M/NoFL), and Group 8 (I/B/NoFL). The arterial filter employed was a 40 micron Pall Arterial Filter ${ }^{\boxplus}$ Model No. AV6SVB. A variety of oxygenators of both adult and paediatric sizes were employed: membrane (Sarns 9461 ${ }^{\circledR}$, Sarns $\mathrm{SMO}^{\circledR}$, COBE VPCML ${ }^{\oplus}$, Medtronic Maxima ${ }^{\oplus}$, Dideco D701 ${ }^{\circledR}$, Dideco D703 ${ }^{\circledast}$, Shiley Plexus ${ }^{\circledast}$, Harvey HF5700 ${ }^{\circledR}$; or bubble (Harvey $\mathrm{H} 700^{\oplus}$, Shiley S100A ${ }^{\oplus}$, Shiley $5070^{\circledR}$, Shiley H100A ${ }^{\circledast}$, Bentley BOS-25 ${ }^{\circledR}$.

Following determination of the control MAC (MACl) for each animal, a one hour observation period 
elapsed and MAC (MAC2) was determined. Following this, anaesthesia was deepened (approximately $0.5 \%$ greater concentration than MAC) and sternotomy performed. Following administration of $400 \mathrm{u} \cdot \mathrm{kg}^{-1}$ heparin, cannulation of the aorta and right atrium was performed and $\mathrm{CPB}$ initiated. The bypass circuit was primed with Plasmalyte ${ }^{\mathrm{R}} \mathrm{A}$ and $500 \mathrm{u}$ heparin were added. Circuit flows were adjusted to provide an estimated flow of $70-80 \mathrm{ml} \cdot \mathrm{kg}^{-1}$ and a mean systemic arterial pressure of $50-70 \mathrm{mmHg}$. Sustained (>one minute) decreases in mean systemic pressure $<50 \mathrm{mmHg}$ were treated with an increase in flow and additional Plasmalyte ${ }^{\mathrm{R}}$. Volatile agent was added to the circuit via the gas inlet in sufficient concentration to prevent movement. Ventilation of the lungs was terminated during $\mathrm{CPB}$. Temperature was maintained in the range of $36-38^{\circ} \mathrm{C}$ by a heat exchanger.

After one hour, $\mathrm{CPB}$ was discontinued, protamine given in a ratio of $1 \mathrm{mg}$ protamine per $10 \mathrm{u}$ heparin to reverse the effects of heparin, haemostasis secured, and MAC (MAC3) was determined. Transfusion of the contents of the oxygenator was performed to improve oxygen-carrying capacity and maintain haemodynamics. Following a one hour observation period, MAC was determined (MAC4). This process was repeated (MAC5) after which the dog was euthanised using Euthanol ${ }^{R}$ (pentobarbital).

A repeated measures ANOVA with group as cofactor determined differences within and between groups for each MAC over time. $P<0.05$ was considered statistically significant. When differences were detected, $t$ tests with Bonferroni correction for multiple comparisons were used to determine where the differences occurred. Based on results from previous experiments from this laboratory, 1,7 it was determined that six animals per group would be sufficient to obtain measurable differences in MAC reduction pre- ps post-CPB.

\section{Results}

The value of MAC prior to $\mathrm{CPB}$ was reproducible and consistent (MACl ps MAC2) within groups but differed between groups treated with isoflurane or enflurane (Figures 1,2). In the enflurane treated groups, MAC was reduced following $\mathrm{CPB}$ in all groups except Group 1 (E/B/FL) (Figure 1). There was some recovery in the degree of $\mathrm{MAC}$ reduction over time amongst the groups in which no arterial filter was utilized. In the isoflurane treated groups, MAC was reduced to the same degree in all groups following CPB (Figure 2). There was no recovery in the degree of MAC reduction over time amongst the groups. There were no important differences among the groups with respect to temperature (range 36.7 to $38.4^{\circ} \mathrm{C}$ ), haemodynamics (Table I), or acid base status (Table II). However the

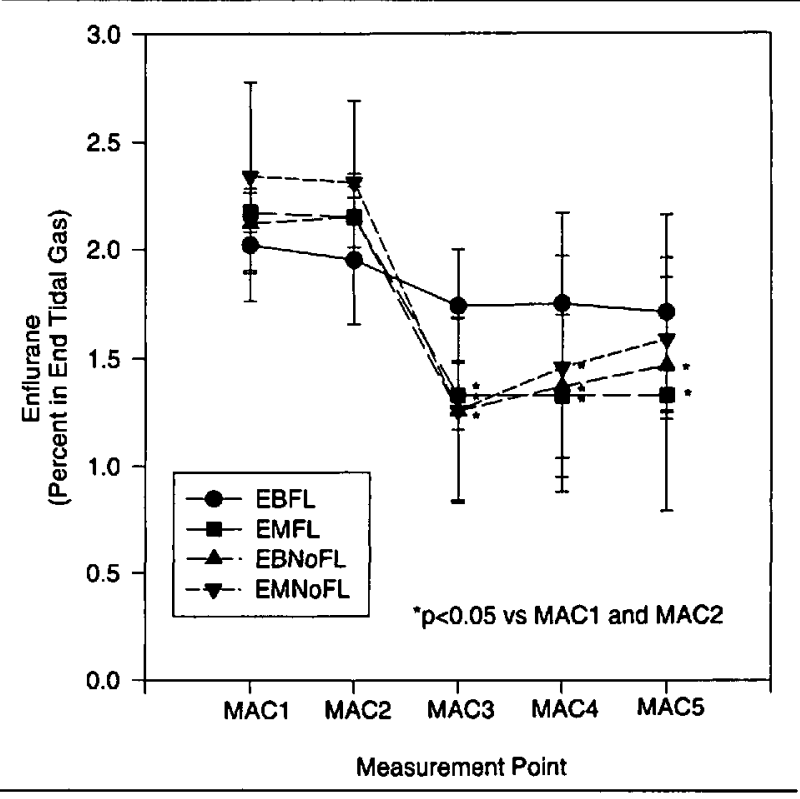

FIGURE I MAC determined before cardiopulmonary bypass (CPB) (MACl, MAC2) and after $1 \mathrm{hr}$ CPB (MAC3, MACA, MAC5). MAC was determined at hourly intervals.

$\mathrm{E}=$ enflurane; $\mathrm{B}=$ bubble oxygenator; $\mathrm{M}=$ membrane oxygenator; $\mathrm{FL}=$ presence of an in-line arterial filter; NoFL $=$ absence of an in-line arterial filter.

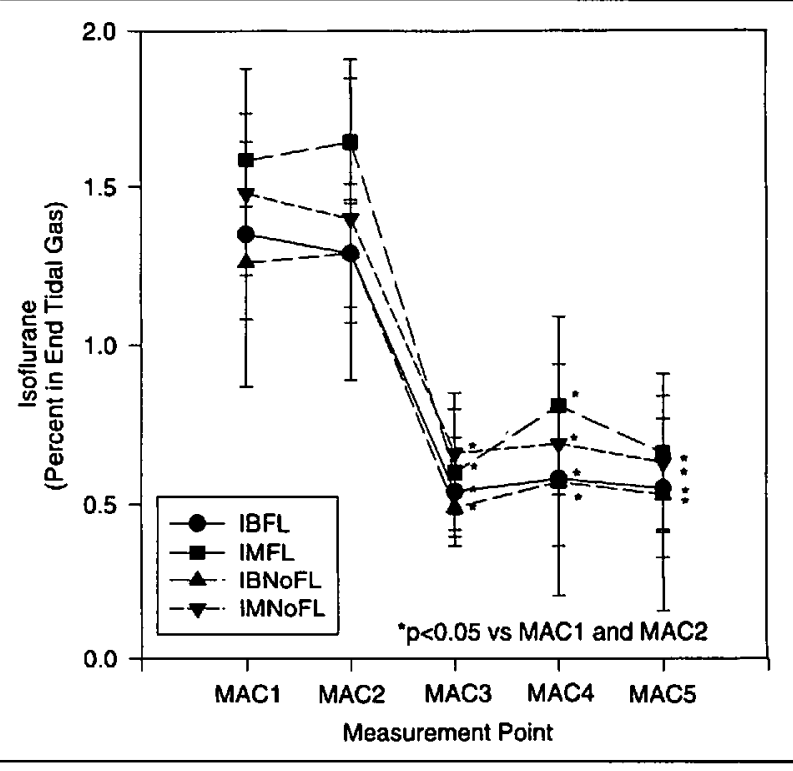

FIGURE 2 MAC determined before cardiopulmonary bypass (CPB) (MACl/MAC2) and after $1 \mathrm{hr}$ CPB (MAC3, MAC4, MAC5). MAC was determined at hourly intervals.

$\mathrm{I}=$ isoflurane; $\mathrm{B}$ = bubble oxygenator; $\mathrm{M}=$ membrane oxygenator; $\mathrm{FL}=$ presence of an in-line arterial filter; NoFL $=$ absence of an inline arterial filter.

level of oxygenation declined (Table II) and haematocrit was reduced in all groups following CPB (range 36 to $39 \%$ from 42 to $51 \%$ pre-CPB). 
TABLE I Hemodynamic measurements following determination of MAC

\begin{tabular}{lllllll}
\hline VARLABLE & GROUP & MAC1 & MAC2 & MAC3 & MAC4 & MAC5 \\
\hline MAP & EBFL & $93 \pm 17$ & $94 \pm 14$ & $64 \pm 11$ & $70 \pm 20$ & $74 \pm 13$ \\
(mmHg) & EMFL & $96 \pm 18$ & $93 \pm 17$ & $62 \pm 25$ & $75 \pm 19$ & $70 \pm 20$ \\
& EBNoFL & $92 \pm 10$ & $93 \pm 19$ & $81 \pm 15$ & $84 \pm 15$ & $81 \pm 15$ \\
& EMNoFL & $98 \pm 15$ & $97 \pm 11$ & $66 \pm 11^{*}$ & $81 \pm 21$ & $74 \pm 31$ \\
& IMFL & $115 \pm 13$ & $114 \pm 9$ & $85 \pm 19$ & $85 \pm 19$ & $80 \pm 12$ \\
& IBFL & $104 \pm 23$ & $105 \pm 20$ & $64 \pm 17$ & $71 \pm 19$ & $61 \pm 23$ \\
& IMNoFL & $90 \pm 20$ & $97 \pm 27$ & $69 \pm 15^{*}$ & $92 \pm 14$ & $88 \pm 17^{*}$ \\
& IBNoFL & $114 \pm 28$ & $93 \pm 22$ & $76 \pm 20^{*}$ & $82 \pm 20^{*}$ & $89 \pm 30^{*}$ \\
\hline
\end{tabular}

(All Results Mean $\pm S D$ ).

$\mathrm{MACl}=$ Control MAC.

MAC2 = MAC determined 1 hour after MAC, pre-cardiopulmonary bypass .

MAC3 = MAC determined immediately after cardiopulmonary bypass.

MAC4 = MAC determined approx 1 hour after MAC3 after cardiopulmonary bypass.

MAC5 = MAC determined approximately 1 hour after MAC4 and approximately $3^{1 / 2} \mathrm{hr}$ after MAC3 after cardiopulmonary bypass. Groups: NF=enflurane; $I F=$ isoflurane; $B=$ bubble oxygenator; $M=$ membrane oxygenator; $F=$ in-line arterial filter present in $C P B$ circuit; $\mathrm{NF}=$ no in-line arterial filter present in $\mathrm{CPB}$ circuit ( $\mathrm{n}=6$ per group).

$* P<0.05$ vs $\mathrm{MACl}-2$

TABLE II Arterial blood gas analysis following determination of MAC

\begin{tabular}{lllllll}
\hline VARIABLE & GROUP & $M A C 1$ & $M A C 2$ & $M A C 3$ & $M A C 4$ & $M A C 5$ \\
\hline $\mathrm{PaO}_{2}$ & EBFL & $477 \pm 83$ & $\mathbf{5 7 2} \pm 184$ & $285 \pm 104^{*}$ & $301 \pm 162^{*}$ & $268 \pm 152^{*}$ \\
$(\mathrm{mmHg})$ & EMFL & $417 \pm 107$ & $\mathbf{4 8 2} \pm 23$ & $291 \pm 96^{*}$ & $206 \pm 140^{\dagger}$ & $229 \pm 120^{\dagger}$ \\
& EBNoFL & $452 \pm 103$ & $493 \pm 114$ & $\mathbf{2 5 2} \pm 97^{\star}$ & $221 \pm 126^{\dagger}$ & $345 \pm 124$ \\
& EMNoFL & $424 \pm 126$ & $435 \pm 73$ & $213 \pm 110$ & $218 \pm 162$ & $293 \pm 158$ \\
& IMFL & $462 \pm 75$ & $453 \pm 119$ & $337 \pm 130$ & $337 \pm 82$ & $349 \pm 156$ \\
& IBFL & $456 \pm 101$ & $502 \pm 139$ & $326 \pm 181$ & $300 \pm 154$ & $286 \pm 172$ \\
& IMNoFL & $438 \pm 94$ & $488 \pm 99$ & $302 \pm 122$ & $279 \pm 96^{*}$ & $302 \pm 149$ \\
& IBNoFL & $448 \pm 73$ & $428 \pm 77$ & $245 \pm 130$ & $245 \pm 163$ & $255 \pm 172$ \\
\hline
\end{tabular}

(All Results Mean $\pm \mathrm{SD}$ ).

$\mathrm{MACl}=$ Control MAC

MAC2 $=$ MAC determined $1 \mathrm{hr}$ after MACl pre-cardiopulmonary bypass.

MAC3 = MAC determined immediately after cardiopulmonary bypass

MAC4 = MAC determined approximately $1 \mathrm{hr}$ after MAC3 after cardiopulmonary bypass.

MAC5 - MAC determined approximately $1 \mathrm{hr}$ after MAC4 and approximately $3 \frac{11 / 2}{\mathrm{hr}}$ after MAC3 following cardiopulmonary bypass.

Groups: $\mathrm{NF}=$ enflurane; $\mathrm{IF}=$ isoflurane; $\mathrm{B}=$ bubble oxygenator; $\mathrm{M}=$ membrane oxygenator; $\mathrm{F}=$ in-line arterial filter present in $\mathrm{CPB}$ circuit; $\mathrm{NF}=$ no in-line arterial filter present in $\mathrm{CPB}$ circuit ( $\mathrm{n}=6$ per group).

${ }^{\star} P<0.05$ vs MAC2: ${ }^{\dagger} P<0.05$ vs MACl \& MAC2

\section{Discussion}

This study has determined that the requirements for enflurane and isoflurane anaesthesia (MAC) were reduced following cardiopulmonary bypass (CPB). Apart from the group receiving enflurane, a bubble oxygenator, and utilizing an in-line arterial filter (Group 1), reductions in MAC for dogs treated with both enflurane and isoflurane occurred regardless of the type of oxygenator (membrane or bubble) or presence or absence of an in-line arterial filter in the circuit. The $10 \%$ reduction in MAC in Group 1 is within the normal variations of values for MAC determinations in our lab and therefore was not different from control values. The isoflurane subset had a slightly greater but not statistically different reduction in MAC post-CPB (i.e., $53-64 \%$ vs $39-46 \%$ for enflurane). These results extend the observations made in our previous report ${ }^{1}$ which determined that enflurane MAC was reduced following CPB employing a bubble oxygenator and no in-line arterial filter. In that study, changes in haematocrit, temperature, and acid base status were not of sufficient magnitude to explain the apparent reduction in anaesthetic requirement. ${ }^{9,10}$ Similarly, in the present study, these variables were controlled, yet reductions in MAC were still observed. 


\section{Microemboli}

We originally speculated that reductions in anaesthetic requirements following $\mathrm{CPB}$ might be due to cerebral injury secondary to microemboli ${ }^{11}$ and our study was designed to address factors affecting microembolic release to the cerebral circulation. ${ }^{12-14}$ The results of the present study suggest that this explanation, while possible, must be modified. Although variably reported as effective, interventions thought to reduce the number of emboli released into the systemic circulation i.e., use of membrane oxygenators, ${ }^{15,16}$ and in-line arterial filtration, ${ }^{14,17}$ did not result in a difference in the degree of $\mathrm{MAC}$ reduction. It may be that changes in anaesthetic requirement following $\mathrm{CPB}$ may, in some way, be related to generation of small microemboli of a size not trapped by an in-line arterial filter. ${ }^{18-21}$ Moody and colleagues $^{22}$ have shown that, following CPB, the brains of subjects who come to autopsy (and dogs subjected to cardiopulmonary bypass) contain microvascular abnormalities which he termed SCADS (small capillary and arteriolar dilatations). The size of these dilatations is approximately $15 \mu$. Widespread microemboli producing brain injury might lead to alterations in anaesthetic requirements. While a membrane oxygenator or an inline arterial filter may reduce the amount of large (i.e., $>40 \mu$ ) emboli, they may not remove all such emboli, ${ }^{23}$ and they do not remove microemboli $<40 \mu .{ }^{15,24}$ Since the aorta of these animals was never fully cross-clamped, release of microemboli due to application of the crossclamp across the aorta and subsequent release of atheromatous debris cannot be invoked as an explanation. ${ }^{14}$

\section{Systemic inflammatory response}

The change in anaesthetic requirement could be due to changes in central nervous system function due to activation of the systemic inflammatory response, which occurs during $\mathrm{CPB}$ independent of microembolic injury. ${ }^{19-21,25}$ Although microemboli may be generated as part of this process ${ }^{26,27}$ their presence may reflect an epiphenomenon as it relates to changes in anaesthetic action. We are unaware of studies employing modalities designed to ameliorate the systemic inflammatory response which have examined the subsequent effect on anaesthetic requirements.

\section{Role of the priming solution}

Antognini suggested that the reductions in MAC post$\mathrm{CPB}$ which we have observed may be related to the use of Plasmalyte $A^{\otimes}$ (containing acetate) in the CPB priming solution. ${ }^{6}$ This suggestion has merit. Acetate is metabolised to Acetyl CoA in peripheral tissues including the brain. ${ }^{28,29}$ The transformation of acetate into Acetyl CoA requires ATP and yields AMP which is sub- sequently converted into adenosine. ${ }^{30}$ Acetate administration reduced sevoflurane MAC by $19 \%{ }^{28}$ and this effect was reversed in the presence of an adenosine receptor blocking agent. Adenosine administration reduced halothane MAC by $49 \%^{31}$ - a figure similar to the degree of MAC reduction observed in the present study. Adenosine reduces CNS norepinephrine concentrations - an effect which has been associated with reduced anaesthetic requirements. ${ }^{32}$ It may well be that a portion of the MAC reduction we have observed post-CPB may be adenosine mediated and this merits further investigation.

\section{Anaesthetic agents}

Volatile anaesthetic agents produce dose-dependent reductions in cerebral metabolic requirements for oxygen $\left(\mathrm{CMRO}_{2}\right)$ with isoflurane being the most potent. They also produce cerebral vasodilatation with isoflurane being least potent ${ }^{33}$ These properties suggested to us in the original design of our study that there might be a difference between the anaesthetics in terms of $\mathrm{MAC}$ reduction post-CPB. No such differences were found, although the absolute degree of $M A C$ reduction with enflurane was slightly less than that of isoflurane.

\section{Other factors affecting cerebral blood flow $w^{33}$}

Factors (such as carbon dioxide management (alpha stat), temperature (normothermia), flow rate and character (mean pressure maintained between 50-70 $\mathrm{mmHg}$ and nonpulsatile in character), and haemodilution) which might affect cerebral blood flow and neurological outcome were not different between groups and do not serve as explanations for our results.

Group 1 demonstrated an inexplicable deviation from the other seven groups following $\mathrm{CPB}$ with respect to MAC reduction. This group, anaesthetized with enflurane and utilizing a bubble oxygenator with an in-line filter, had little change in MAC following $\mathrm{CPB}$. We have no explanation for this observation. Nevertheless, it is important since it may help to explain some of the variability in observations of MAC reduction following CPB reported by ourselves and Antognini and colleagues. ${ }^{1-3,5-7,34}$ It also suggests that the reduction occurring as a result of the use of an acetate containing solution cannot be the only explanation for our observations.

\section{Study limitations}

We have not measured changes in embolic load directly (either in vivo using Doppler techniques or after death using autopsy findings) which limits the strengths of our conclusions regarding the role of microembolism in altering anaesthetic requirements. 
However, we have employed two commonly used surrogate methods designed to limit the embolic load during cardiopulmonary bypass, i.e., use of membrane oxygenators and arterial filters, with no identifiable change in MAC reduction. The generalizability of our findings is enhanced due to the use of a variety of oxygenators, suggesting that a single type of oxygenator is not the reason for differences detected in anaesthetic requirements.

In retrospect, our study would have been enhanced by inclusion of a group receiving a non-acetate priming solution and a sham operated group. At the time we designed the study, it did not occur to us to examine these variables, and we believe that their inclusion would have greatly complicated the study design by increasing the variables being examined, and number of animals required to determine if differences existed.

We did not measure glucose concentration. It is possible that some of our findings might be attributable to hypoglycaemia or hyperglycaemia. ${ }^{35}$ We consider the possibility of hypoglycaemia to be remote given that all animals were healthy and the development of hyperglycaemia to the extent required to alter MAC seems unlikely given the nature of the surgery and our previous experience with the model in which the animals were allowed to recover without apparent neurological sequelae. ${ }^{7}$

In summary, we have demonstrated that $\mathrm{MAC}$ reduction following $\mathrm{CPB}$ is independent of the volatile agent used (enflurane vs isoflurane), type of oxygenator employed (membrane vs bubble), or presence or absence of an in-line arterial filter in the bypass circuit. The aetiology for the reduction in anaesthetic requirements following CPB remains unknown but the theory that it is related to microembolisation appears less likely.

\section{Acknowledgments}

The authors wish to thank Polly Moores for secretarial assistance in the preparation of this manuscript and Dr. Tom Coonan for reviewing the manuscript.

\section{References}

1 Hall RI, Sullivan JA. Does cardiopulmonary bypass alter enflurane requirements for anesthesia? Anesthesiology 1990; 73: 249-55.

2 Antognini JF, Kien ND. Cardiopulmonary bypass does not alter canine enflurane requirements. Anesthesiology 1992; 76: 953-7.

3 Borges $M$, Antognini JF. Does the brain influence somatic responses to noxious stimuli during isoflurane anesthesia? Anesthesiology 1994; 81: 1511-5.
4 Antognini JF, Schwartz K. Exaggerated anesthetic requirements in the preferentially anesthetized brain. Anesthesiology 1993; 79: 1244-9.

5 Antognini JF. Hypothermia eliminates isoflurane requirements at $20^{\circ} \mathrm{C}$. Anesthesiology 1993; 78: 1152-6.

6 Antognini JF. Anesthetic requirements decrease after cardiopulmonary bypass (Letter). Anesthesiology 1993; 79: 1443-4.

7 Doak GJ, Li G, Hall RI, Sullivan JA. Does hypothermia or hyperventilation affect enflurane MAC reduction following partial cardiopulmonary bypass in dogs? Can J Anaesth 1993; 40: 176-82.

8 Eger EI II, Saidman LJ, Brandstater B. Minimum alveolar anesthetic concentration: a standard of anesthetic potency. Anesthesiology 1965; 26: 756-63.

9 Cullen DJ. Anesthetic depth and MAC. In: Miller RD (Ed.). Anesthesia, 1st ed. New York: Churchill Livingstone, 1986: 553-80.

10 Cullen DJ, Eger EI II. The effects of hypoxia and isovolemic anemia on the halothane requirement (MAC) of dogs. III. The effects of acute isovolemic anemia. Anesthesiology 1970; 32: 46-50.

11 Aberg $T$, Ronquist $G$, Tyden $H$, et al. Adverse effects on the brain in cardiac operations as assessed by biochemical, psychometric, and radiologic methods. I Thorac Cardiovasc Surg 1984; 87: 99-105.

12 Orenstein JM, Sato N, Aaron B, Bucholz B, Bloom S. Microemboli observed in deaths following cardiopulmonary bypass surgery: silicone antifoam agents and polyvinyl chloride tubing as sources of emboli. Hum Pathol 1982; 13: 1082-90.

13 Henriksen L, Hjelms E, Lindeburgh T. Brain hyperperfusion during cardiac operations. J Thorac Cardiovasc Surg 1983; 86: 202-8.

14 Clark RE, Brillman J, Davis DA, Lovell MR, Price TRP, Magovern GJ. Microemboli during coronary artery bypass grafting. Genesis and effect on outcome. J Thorac Cardiovasc Surg 1995; 109: 249-58.

15 Blauth CI, Smith PL, Arnold JV, Jagoe JR, Wootton R, Taylor KM. Influence of oxygenator type on the prevalence and extent of microembolic retinal ischemia during cardiopulmonary bypass. J Thorac Cardiovasc Surg 1990; 99: 61-9.

16 Padayachee TS, Parsons S, Theobold R, Linley J, Gosling $R G$, Deverall $P B$. The detection of microemboli in the middle cerebral artery during cardiopulmonary bypass: a transcranial Doppler ultrasound investigation using membrane and bubble oxygenators. Ann Thorac Surg 1987; 44: 298-302.

17 Pugsley W, Klinger L, Paschalis C, Treasure T, Harrison $M$, Newman $S$. The impact of microemboli during cardiopulmonary bypass on neuropsychological functioning. Stroke 1994; 25 : 1393-9. 
18 Herskowitz A, Mangano DT. Inflammatory cascade. A final common pathway for perioperative injury? (Editorial). Anesthesiology 1996; 85: 957-60.

19 Coceani F, Lees J, Mancilla J, Belizario J, Dinarello CA. Interleukin- 6 and tumor necrosis factor in cerebrospinal fluid: changes during pyrogen fever. Brain Res 1993; 612: 165-71

20 Klir J, Roth J, Szelényi Z, McClellan JL, Kluger MJ. Role of hypothalamic interleukin- 6 and tumor necrosis factor- $\alpha$ in LPS fever in rat. Am J Physiol 1993; 265 : R512-7.

21 Butler J, Rocker GM, Westaby S. Inflammatory response to cardiopulmonary bypass. Ann Thorac Surg 1993; 55: 552-9.

22 Moody DM, Bell MA, Challa VR, Jobnston WE, Prough $D S$. Brain microemboli during cardiac surgery or aortography. Ann Neurol 1990; 28: 477-86.

23 Blauth CI, Arnold JV, Schulenberg WE, McCartney AC, Taylor KM. Cerebral microembolism during cardiopulmonary bypass. Retinal microvascular studies in vivo with fluorescein angiography. J Thorac Cardiovasc Surg 1988; 95: 668-76.

24 Gervin AS, McNeer JF, Wolfe WG, Puckett CL, Silver D. Ultrapore hemofiltration during extracorporeal circulation. J Thorac Cardiovasc Surg 1974; 67: 237-42.

25 Pollmächer $T$, Schreiber W, Gudewill S, et al. Influence of endotoxin on nocturnal sleep in humans. Am J Physiol 1993; 264: R1077-83.

26 Cavarocchi NC, Pluth JR, Schaff HV, et al. Complement activation during cardiopulmonary bypass. Comparison of bubble and membrane oxygenators. J Thorac Cardiovasc Surg 1986; 91: 252-8.

27 Hammerschmidt DE, Stroncek DF, Bowers TK, et al. Complement activation and neutropenia occurring during cardiopulmonary bypass. J Thorac Cardiovasc Surg 1981; 81: 370-7.

28 Carmichael FJ, Israel $\Upsilon$, Crawford $M$, et al. Central nervous system effects of acetate: contribution to the central effects of ethanol. J Pharmacol Exp Ther 1991; 259: 403-8.

29 Beryl S, Frigyesi TL. The turnover of glutamate, glutamine, aspartate and $\mathrm{GABA}$ labeled with $\left[1-{ }^{14} \mathrm{C}\right]$ acetate in caudate nucleus, thalamus and motor cortex (cat). Brain Res 1969; 12: 444-55.

30 Kiviluoma KT, Peubkurinen KJ, Hassinen IE. Adenine nucleotide transport and adenosine production in isolated rat heart mitochondria during acetate metabolism. Biochim Biophys Acta 1989; 974: 274-81.

31 Seitz PA, ter Riet $M$, Rush $W$, Merrell WJ. Adenosine decreases the minimum alveolar concentration of halothane in dogs. Anesthesiology 1990; 73: 990-4.

32 Miller RD, Way WL, Eger EI II. The effects of alphamethyldopa, reserpine, guanethidine, and iproniazid on minimum alveolar anesthetic requirement (MAC). Anesthesiology 1964; 29: 1153-8.

33 O'Dwyer C, Prough DS, Johnston WE. Determinants of cerebral perfusion during cardiopulmonary bypass. J Cardiothorac Vasc Anesth 1996; 10: 54-65.

34 Hall RI, Sullivan J. Anesthetic requirements decrease after cardiopulmonary bypass (Letter). Anesthesiology 1993; 79: 1443.

35 Lebot J, Piriz H, Villard J, Coben R, Guidollet J. Glucose homeostasis. Comparison between hypothermic and normothermic cardiopulmonary bypass. Chest 1992; 102: 106-11. 